\title{
Injurious Ventilatory Strategies Increase Cytokines and c-fos m-RNA Expression in an Isolated Rat Lung Model
}

\author{
Lorraine Tremblay, ${ }^{\star}$ Franco Valenza, ${ }^{\ddagger}$ Sergio P. Ribeiro, ${ }^{\ddagger}$ Jingfang Li, ${ }^{\ddagger}$ and Arthur S. Slutsky ${ }^{\ddagger}$ \\ *Division of General Surgery and Division of Thoracic Surgery, The Toronto Hospital, Toronto, M5G 1L7; and ${ }^{\ddagger}$ Division of Respiratory \\ Medicine, Mount Sinai Hospital, Samuel Lunenfeld Research Institute, University of Toronto, Toronto, M5G 1 X5 Canada
}

\begin{abstract}
We examined the effect of ventilation strategy on lung inflammatory mediators in the presence and absence of a preexisting inflammatory stimulus. 55 Sprague-Dawley rats were randomized to either intravenous saline or lipopolysaccharide (LPS). After 50 min of spontaneous respiration, the lungs were excised and randomized to $2 \mathrm{~h}$ of ventilation with one of four strategies: (a) control (C), tidal volume $\left(V_{t}\right)=7$ $\mathrm{cc} / \mathrm{kg}$, positive end expiratory pressure $(\mathrm{PEEP})=3 \mathrm{~cm} \mathrm{H} \mathrm{H}_{2}$ (b) moderate volume, high PEEP (MVHP), $V_{\mathrm{t}}=15 \mathrm{cc} / \mathrm{kg}$; PEEP = $10 \mathrm{~cm} \mathrm{H}_{2} \mathrm{O}$; (c) moderate volume, zero PEEP $(\mathrm{MVZP}), V_{\mathrm{t}}=15 \mathrm{cc} / \mathrm{kg}, \mathrm{PEEP}=0$; or $(d)$ high volume, zero PEEP (HVZP), $V_{\mathrm{t}}=40 \mathrm{cc} / \mathrm{kg}$, PEEP $=0$. Ventilation with zero PEEP (MVZP, HVZP) resulted in significant reductions in lung compliance. Lung lavage levels of TNF $\alpha$, IL$1 \beta$, IL-6, IL-10, MIP-2, and IFN $\gamma$ were measured by ELISA. Zero PEEP in combination with high volume ventilation (HVZP) had a synergistic effect on cytokine levels (e.g., 56fold increase of $\mathrm{TNF} \alpha$ versus controls). Identical end inspiratory lung distention with PEEP (MVHP) resulted in only a three-fold increase in TNF $\alpha$, whereas MVZP produced a six-fold increase in lavage $T N F \alpha$. Northern blot analysis revealed a similar pattern $(\mathrm{C}$, MVHP $<$ MVZP $<$ HVZP) for induction of c-fos mRNA. These data support the concept that mechanical ventilation can have a significant influence on the inflammatory/anti-inflammatory milieu of the lung, and thus may play a role in initiating or propagating a local, and possibly systemic inflammatory response. (J. Clin. Invest. 1997. 99:944-952.) Key words: tumor necrosis factor • bronchoalveolar lavage fluid • leukotrienes $\bullet$ inflammation $\bullet$ respiration $\bullet$ artificial
\end{abstract}

\section{Introduction}

Over the past 30-40 years, mechanical ventilation has become an indispensable therapeutic modality for the treatment of respiratory failure. However, soon after its inception, it became apparent that mechanical ventilation per se could lead to a number of serious complications, including initiation or exac-

Address correspondence to Dr. A.S. Slutsky, Mount Sinai Hospital, 600 University Avenue, Room 656A, Toronto, Ontario, Canada, M5G 1X5. Phone: (416) 586-5298; FAX: (416) 586-8558; E-mail: arthur.slutsky@utoronto.ca

Received for publication 15 April 1996 and accepted in revised form 9 December 1996.

J. Clin. Invest.

(C) The American Society for Clinical Investigation, Inc. 0021-9738/97/03/0944/07 \$2.00

Volume 99, Number 5, March 1997, 944-952 erbation of underlying lung injury. Research over the past two decades has focused primarily on the mechanical forces (i.e., pressures and volumes) producing ventilator-induced lung injury $(1,2)$. Despite intense research and a number of innovations in ventilatory therapy aimed at minimizing such injury, however, the morbidity and mortality of acute respiratory failure remains high (3), and ventilator-induced lung injury remains a significant problem in the care of critically ill patients (4). In patients developing adult respiratory distress syndrome (ARDS), ${ }^{1}$ only a small percentage go on to die of respiratory failure (3). Lung injury, rather, appears to predispose patients to the development of a systemic inflammatory response that culminates in multiple organ dysfunction syndrome (MODS) and death $(3,5)$.

One possible explanation for this observation is that mechanical ventilation (invariably used in ARDS) serves to initiate and/or potentiate an inflammatory response in the lung that in turn propagates a vicious cycle of inflammation leading to tissue injury locally, and possibly systemically. Although no studies to date have addressed whether mechanical ventilation per se is capable of altering lung cellular function leading to production of inflammatory mediators and lung injury, there is some evidence in the literature to support the plausibility of this postulate. Clinical studies of patients developing ARDS have noted an association between lung inflammatory mediators and the development of physiologic abnormalities (6-8). Studies in a rabbit model of ARDS have found that conventional mechanical ventilation as opposed to high frequency oscillatory ventilation led to increased neutrophil infiltration and activation, as well as increased lung lavage levels of plateletactivating factor and thromboxane- $\mathrm{B}_{2}(9-11)$. Concurrent with these physiological studies, research over the past decade has shown that mechanotransduction (i.e., the conversion of a mechanical stimulus such as cell deformation into biochemical and molecular alterations) plays a crucial role in determining the structure and function of a number of tissues, including the lung (12-14). Studies in vitro and in vivo have found that both the degree and the pattern of mechanical stretch are important in determining cell responses $(14,15)$. Given that mechanical ventilation alters both the pattern and magnitude of lung stretch, it is not unreasonable to postulate that alterations in gene expression or cellular metabolism may arise.

1. Abbreviations used in this paper: ARDS, adult respiratory distress syndrome; bpm, breaths per minute; $\mathrm{C}$, control, HVZP, group ventilated with large tidal volume and zero positive end expiratory pressure; LPS, lungs preexposed to inflammatory stimulus; MODS, multiple organ dysfunction syndrome; MVHP, group ventilated with a moderate tidal volume and high positive end expiratory pressure; MVZP, group with intermediate degree of lung stretch in absence of positive end expiratory pressure; PEEP, positive end expiratory pressure; TLC, total lung capacity; $\mathrm{V}_{\mathrm{t}}$, tidal volume. 
In this study we examined the hypothesis that particular ventilation strategies of either healthy lungs or lungs preexposed to an inflammatory stimulus (LPS) could lead to changes in the lung inflammatory milieu as assessed by bronchoalveolar lavage levels of inflammatory and anti-inflammatory cytokines. The effect of these ventilation strategies on the activation of lung cells at the transcriptional level was also determined for $\mathrm{TNF} \alpha$ and c-fos (a representative immediateearly response gene with a stretch responsive promoter [16]). Our data support the hypothesis that specific patterns of ventilation per se can produce or magnify the inflammatory response in the lung, and thus suggest a mechanism whereby mechanical ventilation could lead to lung injury, as well as potentially contribute to the development of a systemic inflammatory response.

\section{Methods}

Animal model and interventions. The effect of four different ventilatory strategies on the production of inflammatory mediators in ex vivo isolated lungs was studied in the presence or absence of LPSinduced sepsis. 55 male Sprague Dawley rats (Charles River Labs, St. Constant, Quebec, Canada) were randomized in a blinded fashion to receive either $20 \mathrm{mg} / \mathrm{kg}$ of Salmonella typhosa lipopolysaccharide (Lot 81H4018; Sigma Chemical Co., St. Louis, MO) or an equivalent volume of normal saline intravenously via the dorsal penile vein under ketamine ( $75 \mathrm{mg} / \mathrm{kg}$ i.p.) and acepromazine ( $2.5 \mathrm{mg} / \mathrm{kg}$ i.p.) anesthesia. After $50 \mathrm{~min}$ of spontaneous respiration to allow for development of a septic response, the lungs were excised via a midline sternotomy after induction of anesthesia with sodium pentobarbital (37 mg/kg i.p.) and systemic heparinization (500 IU/kg i.v.). $4 \mathrm{ml}$ of blood were withdrawn from the right ventricle during lung harvest, centrifuged (Hettich Mikroliter D-7200; Diamed Lab Supplies Inc., Mississauga, Ont.) at $4^{\circ} \mathrm{C}, 3,000 \mathrm{~g}$ for $10 \mathrm{~min}$, and the serum frozen at $-70^{\circ} \mathrm{C}$ for subsequent determination of baseline levels of circulating cytokines. The excised lungs were placed in a $37^{\circ} \mathrm{C}$ humidified chamber, and airway pressures were transduced (HP 45 transducer; Validyne Engineering Corp., Northridge, CA) and recorded (Gould ES 1,000 recorder; Gould Inc., Cleveland, $\mathrm{OH}$ ) over the ventilation period. Before initiating ventilation, the lungs were inflated twice to total lung capacity (TLC, defined as a transpulmonary pressure of 25 $\mathrm{cm} \mathrm{H}_{2} \mathrm{O}$ ), followed by determination of static pressure-volume curves, by stepwise injections/withdrawals of 0.5 to $1 \mathrm{~cm}^{3}$ aliquots of air to a transpulmonary pressure of $25 \mathrm{~cm} \mathrm{H}_{2} \mathrm{O}$.

The lungs were then randomized to one of four ventilatory strategies, applied using a small animal, volume cycled ventilator (Harvard Rodent Ventilator, Model 683; Harvard Apparatus, South Natick, MA). Controls (C) received a relatively noninjurious ventilatory strategy consisting of $3 \mathrm{~cm} \mathrm{H}_{2} \mathrm{O}$ positive end expiratory pressure (PEEP), a tidal volume $\left(\mathrm{V}_{\mathrm{t}}\right)$ of $7 \mathrm{~cm}^{3} / \mathrm{kg}$, and a respiratory rate of 40 breaths per minute (bpm) with room air. To assess the effect of lung overdistention in the presence or absence of PEEP, we included a group ventilated with a large tidal volume with zero PEEP (HVZP: $\mathrm{V}_{\mathrm{t}}=40 \mathrm{~cm}^{3} / \mathrm{kg}$, PEEP $\left.=0 \mathrm{~cm} \mathrm{H}_{2} \mathrm{O}, 40 \mathrm{bpm}\right)$, and a group ventilated with a moderate tidal volume and a high PEEP (MVHP: $V_{t}=15 \mathrm{~cm}^{3} /$ $\mathrm{kg}, \mathrm{PEEP}=10 \mathrm{~cm} \mathrm{H}_{2} \mathrm{O}, 40 \mathrm{bpm}$ ). These values were chosen based on a series of preliminary experiments performed using a plethysmograph to determine two ventilatory strategies with identical endinspiratory lung volumes. The fourth strategy consisted of an intermediate degree of lung stretch in the absence of PEEP (MVZP: $\mathrm{V}_{\mathrm{t}}=$ $15 \mathrm{~cm}^{3} / \mathrm{kg}, \mathrm{PEEP}=0 \mathrm{~cm} \mathrm{H}_{2} \mathrm{O}, 40 \mathrm{bpm}$ ). All ex vivo ventilations were started $20 \mathrm{~min}$ after induction of anesthesia for lung harvest.

Upon completion of $2 \mathrm{~h}$ of ex vivo ventilation, static lung compliance curves were determined again as described above. The left lung was then lavaged three times using 2-ml aliquots of normal saline. The effluents were pooled, centrifuged (model TJ-6; Beckman Instru- ments, Inc., Palo Alto, CA) at 2,000 rpm for $10 \mathrm{~min}$, and the supernatants frozen at $-70^{\circ} \mathrm{C}$. The left lung was excised, snap-frozen, and stored at $-70^{\circ} \mathrm{C}$ for tissue RNA extraction.

Following analysis of the data, the above experimental protocol was repeated using 24 non-septic rats randomized to one of the four ventilatory strategies, with a gas mixture of room air supplemented with $5 \% \mathrm{CO}_{2}$. This was done in order to determine the effect of cellular alkalosis, secondary to the different ventilatory strategies, on our results.

All animals received humane care in compliance with the Principles of Laboratory Animal Care formulated by the Institute of Laboratory Animal Resources, the Guide for the Care and Use of Laboratory Animals published by the National Institute of Health (NIH Publication 86-23,1985), and the Guide to the Care and Use of Experimental Animals formulated by the Canadian Council of Animal Care (CCAC 2nd Ed. 1993).

Cytokine ELISAs and lung lavage total protein concentration. Cytokine analysis on the serum (TNF- $\alpha$, IL-1 $\beta$ ) and lavage fluid (TNF- $\alpha$, IL-1 $\beta$, IL-6, IL-10, IFN $\gamma$, MIP-2) was carried out in duplicate in a blinded fashion using commercially available ELISA kits (Biosource Int'l., Camarillo, CA). The lower detection limit for these kits is 4,7,8,13,13, and $1 \mathrm{pg} / \mathrm{ml}$ respectively. Three of these kits were specific for rat (TNF $\alpha$, IFN $\gamma$, MIP2), while the remaining three were murine kits with cross-reactivity with the comparable rat cytokine. The absorbance of each well was read at $450 \mathrm{~nm}$ with a MR600 microplate reader (Dynatech Laboratories, Chantilly, VA). Background absorbency of blank wells was subtracted from the standards and unknowns prior to determination of sample concentrations.

Total protein concentration in each of the lung lavage specimens was determined in duplicate as per the protocol for the Coomassie Protein Assay (Pierce, Rockford, IL), using bovine serum albumin to construct the standard curve.

Northern blot analysis. Total cellular RNA was extracted from frozen lung tissue using guanidine isothiocyanate as previously described (17). Aliquots of RNA were size-fractionated by $1.5 \%$ agaroseformaldehyde gel electrophoresis, transferred to Hybond-N membranes (Amersham Canada Ltd., Oakville, Ont.) and hybridized with $\left[{ }^{32} \mathrm{P}\right] \mathrm{dCTP}$ random-primed probes for $\mathrm{c}-\mathrm{fos}$ and $\mathrm{TNF} \alpha$ sequentially. The cDNA probes for c-fos and TNF $\alpha$ were generously donated by Asahi Chemical Industry Co. Ltd. (Tokyo, Japan), and Dr. D. Templeton (Department of Clinical Biochemistry, University of Toronto, Canada), respectively. Relative amounts of specific mRNA were quantified by NIH Image version 1.5 software for MacIntosh computers, and standardized to $28 \mathrm{~S}$ ribosomal RNA.

Statistical analysis and exclusion criteria. Data were analyzed by PC computer using SigmaStat for Windows, Version 1.0 (Jandel Corporation, San Rafael, CA). The sample size was determined (based on preliminary experiments) to be 48 animals ( $n=6$ per group) in order to detect a difference in cytokine concentration of 0.50 , an estimated standard deviation of 0.20 , a power of 0.80 , and an $\alpha$ value of 0.05 . Exclusion criteria included development of significant airleaks (such that comparable lung distention could not be attained), or death before lung harvest. All exclusions were replaced in the randomization process. Comparison of groups for effect of ventilation strategy and LPS was carried out using two-way analyses of variance with the Student-Newman-Keuls correction for multiple comparisons as appropriate (18). Analysis of shifts in compliance curves was performed using paired $t$ tests (18). Significance was set at $P \leq 0.05$. Results are presented graphically as mean with standard deviation bars.

\section{Results}

Seven experiments were excluded due to the development of significant air leaks following initiation of ventilation (one MVHP, five HVZP) or during lung harvest (one). All excluded experiments were replaced in the randomization pro- 
Table I. Peak Airway Pressures during Ex Vivo

Ventilation Period

\begin{tabular}{|c|c|c|c|c|c|}
\hline $\begin{array}{l}\text { Ventilation } \\
\text { strategy* }\end{array}$ & $\begin{array}{l}\text { Study } \\
\text { group }\end{array}$ & $30 \mathrm{~min}$ & $60 \mathrm{~min}$ & $90 \mathrm{~min}$ & $120 \mathrm{~min}$ \\
\hline & & $\mathrm{cm} \mathrm{H}_{2} \mathrm{O}$ & $\mathrm{cm} \mathrm{H} \mathrm{H}_{2} \mathrm{O}$ & $\mathrm{cm} \mathrm{H} \mathrm{H}_{2} \mathrm{O}$ & $\mathrm{cm} \mathrm{H}_{2} \mathrm{O}$ \\
\hline \multirow[t]{2}{*}{ Control } & Saline & $9.3 \pm 1.4$ & $10.8 \pm 2.0$ & $11.8 \pm 1.9$ & $13.1 \pm 1.7$ \\
\hline & LPS & $9.6 \pm 2.9$ & $10.9 \pm 0.5$ & $12.5 \pm 3.3$ & $14.2 \pm 3.1$ \\
\hline \multirow[t]{2}{*}{ MVHP } & Saline & $56.2 \pm 3.3$ & $53.5 \pm 3.6$ & $52.4 \pm 3.2$ & $50.9 \pm 3.4$ \\
\hline & LPS & $60.3 \pm 3.9$ & $58.7 \pm 3.6$ & $56.7 \pm 4.1$ & $55.8 \pm 4.4$ \\
\hline \multirow[t]{2}{*}{ MVZP } & Saline & $23.3 \pm 2.9$ & $25.2 \pm 3.3$ & $26.4 \pm 4.5$ & $27.6 \pm 5.2$ \\
\hline & LPS & $24.3 \pm 4.5$ & $26.0 \pm 4.0$ & $29.2 \pm 4.5$ & $30.0 \pm 3.6$ \\
\hline \multirow[t]{2}{*}{ HVZP } & Saline & $41.1 \pm 4.3$ & $42.7 \pm 4.4$ & $44.2 \pm 5.1$ & $46.7 \pm 6.7$ \\
\hline & LPS & $43.2 \pm 5.5$ & $42.1 \pm 4.4$ & $43.9 \pm 4.9$ & $46.4 \pm 5.3$ \\
\hline
\end{tabular}

* Control peak airway pressure $\left(\mathrm{P}_{\mathrm{aw}}\right)<\mathrm{MVZP}<\mathrm{MVHP}$, HVZP $(P<$ $0.05)$. No significant changes in peak $P_{a w}$ were observed for identical ventilation strategies over time, or in the presence or absence of LPS.

cess such that there were six animals per group in the final analysis.

There were no significant differences among study groups with respect to rat weight $(407 \pm 41 \mathrm{~g}) .50 \mathrm{~min}$ after intravenous LPS, all rats had significantly elevated serum TNF $\alpha$ concentrations $(7050 \pm 2848 \mathrm{pg} / \mathrm{ml})$ as compared to those receiving saline $(54 \pm 37 \mathrm{pg} / \mathrm{ml}, P<0.0001)$. No significant differences in baseline serum TNF $\alpha$ were found among the four ventilation strategies for either saline- or LPS-treated animals. Serum IL-1 $\beta$ was not detectable at the time of lung harvest in any group.

LPS pretreatment did not significantly alter peak airway pressures as compared to the saline-treated animals randomized to the same ventilation strategy (Table I). Likewise, no
Table II. Pooled Lung Lavage Returns and Total Protein Concentration

\begin{tabular}{|c|c|c|c|c|}
\hline & Control & MVHP & MVZP & HVZP \\
\hline \multicolumn{5}{|c|}{ Volume of returns (ml) } \\
\hline Saline & $4.2 \pm 0.3$ & $4.4 \pm 0.3$ & $3.9 \pm 0.3$ & $4.3 \pm 0.1$ \\
\hline$* 5 \% \mathrm{CO}_{2}$ & $4.4 \pm 0.1$ & $4.4 \pm 0.1$ & $4.3 \pm 0.1$ & $4.4 \pm 0.1$ \\
\hline LPS & $4.1 \pm 0.3$ & $4.4 \pm 0.1$ & $3.8 \pm 0.2$ & $4.3 \pm 0.2$ \\
\hline \multicolumn{5}{|c|}{ Lavage protein concentration $(\mu \mathrm{g} / \mathrm{ml})$} \\
\hline Saline & $113 \pm 33$ & $\$_{284 \pm 50}$ & $\S 385 \pm 102$ & "1994 \pm 372 \\
\hline$* 5 \% \mathrm{CO}_{2}$ & $87 \pm 38$ & $\S_{247 \pm 46}$ & $\$ 389 \pm 110$ & $\pi 1736 \pm 247$ \\
\hline LPS & $126 \pm 22$ & $\S_{250 \pm 48}$ & $\|_{423 \pm 112}$ & $\pm \pi 2449 \pm 272$ \\
\hline
\end{tabular}

*Repeat experiments ventilating non-septic lung with room air $+5 \%$ $\mathrm{CO}_{2} ;{ }^{\ddagger} \mathrm{HVZP}$ LPS $>$ saline, $P=0.04 ;{ }^{\S} P<0.05$ vs. Control; ${ }^{\|} P<0.05$ vs. Control, MVHP; ${ }^{\mathbb{P}} P<0.05$ vs. Control, MVHP, MVZP.

significant changes in peak airway pressures occurred over the ventilation period. The lowest airway pressures were observed in the control group (C). The peak airway pressures for the two ventilatory strategies with comparable end-inspiratory lung volumes (MVHP, HVZP), were not significantly different.

Static pressure volume curves for each study group prior to and following the period of ex vivo ventilation are shown in Fig. 1. No shift in the curves was seen in the high PEEP group (MVHP). A small but insignificant shift to the right was observed in the control lungs (C). However, in the absence of PEEP, a significant reduction in lung compliance developed following $2 \mathrm{~h}$ of ventilation $(P<0.0005$ for MVZP and HVZP).

The volume of lung lavage returns for the ventilatory strat-

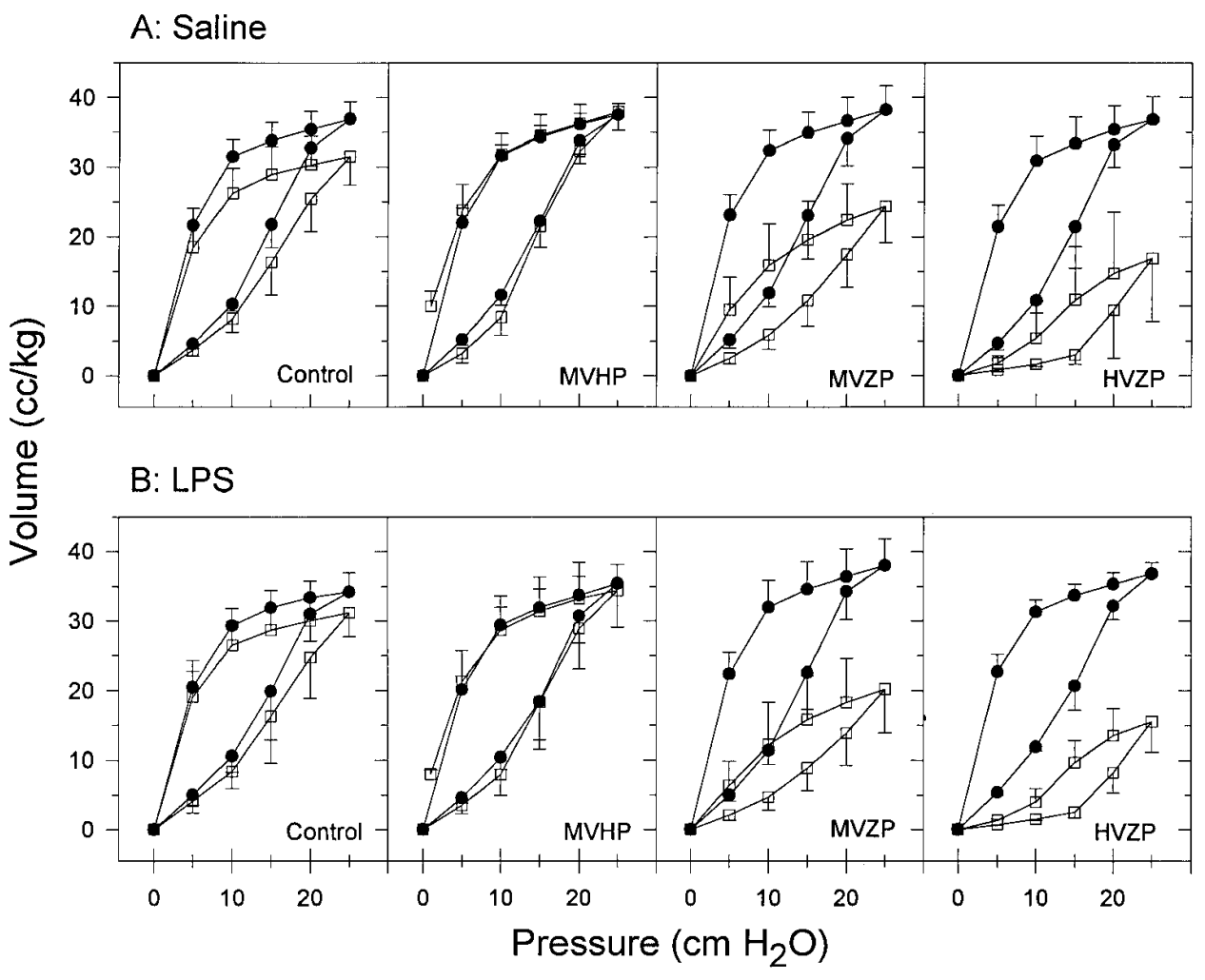

Figure 1. Static compliance curves of the lungs prior to ex vivo ventilation (-) and following $2 \mathrm{~h}$ of ex vivo ventilation ( $\square$ ). A significant rightward shift developed in both zero PEEP groups $(P<0.005$ for MVZP, HVZP), whereas no shift was observed in the presence of 10 $\mathrm{cm}$ of PEEP for either saline- or LPS-treated lungs. 

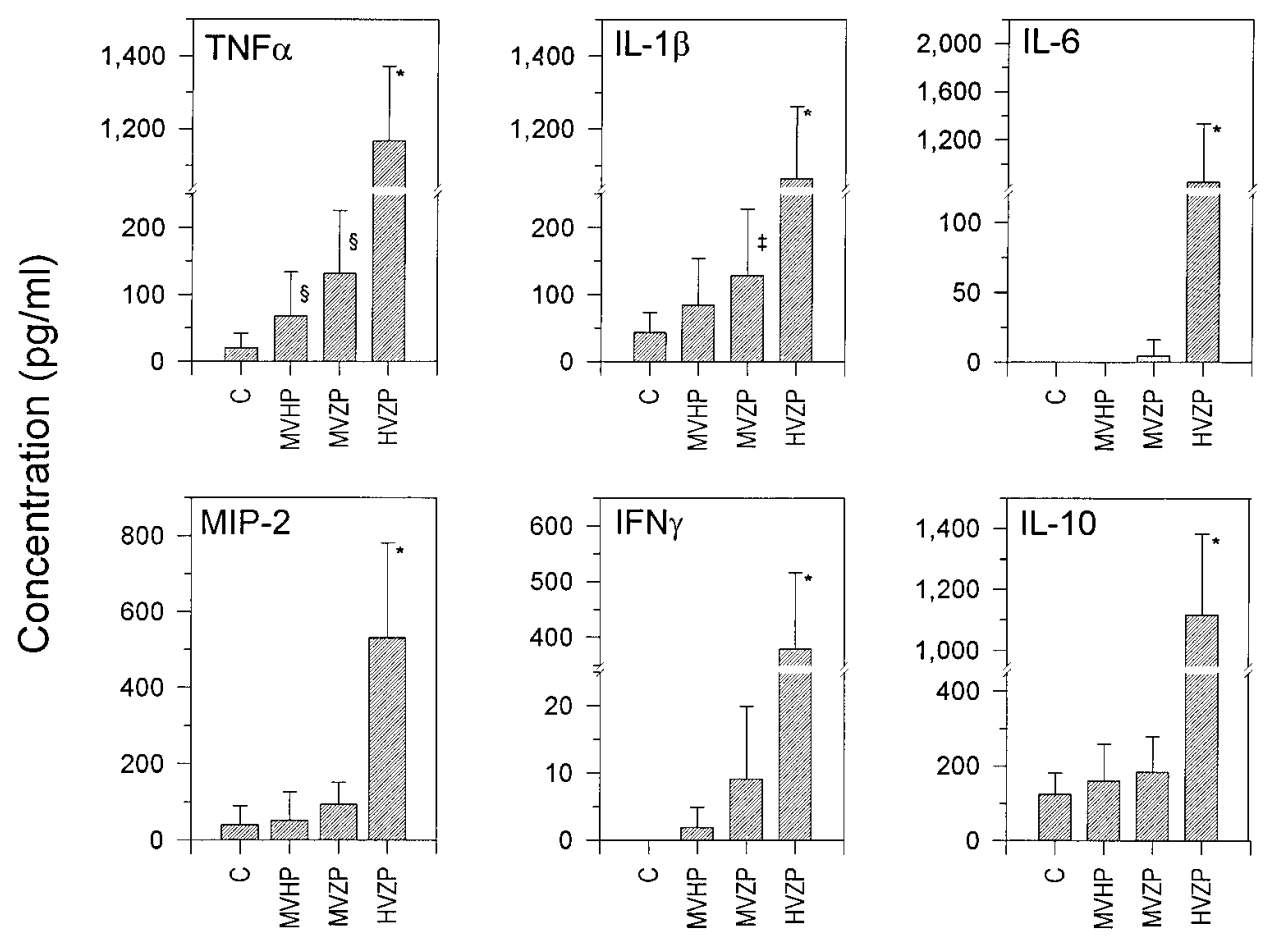

Figure 2. Effect of ventilation strategy on absolute lung lavage cytokine concentrations for the salineinjected groups. A similar trend was seen for all cytokines with lowest levels in the control group $(C)$ and highest in HVZP. Despite similar end-expiratory distention, MVHP ventilation had significantly lower BAL cytokine concentrations than HVZP ventilation. $* P<0.05$ vs. Control, MVHP, MVZP; ${ }^{\ddagger} P<0.05$ vs. Control, MVHP; ${ }^{\S} P<0.05$ vs.

Ventilation Strategy Control.

egies were similar (Table II). Highest total protein concentrations were found in the HVZP lung lavage for all treatment strategies, with lowest total protein concentrations in the lavage of those lungs subjected to control ventilation (Table II). Within ventilatory strategies, there were no significant differences in lung lavage protein concentration (aside from an in- creased protein concentration in the LPS-treated HVZP group, as compared to the saline-treated HVZP group).

Fig. 2 demonstrates the absolute levels of various inflammatory and anti-inflammatory cytokines in the lavage fluid of lungs randomized to intravenous saline. The lowest levels of inflammatory cytokines (TNF $\alpha$, IL-1 $\beta$, IL-6, MIP-2, and IFN $\gamma$ )
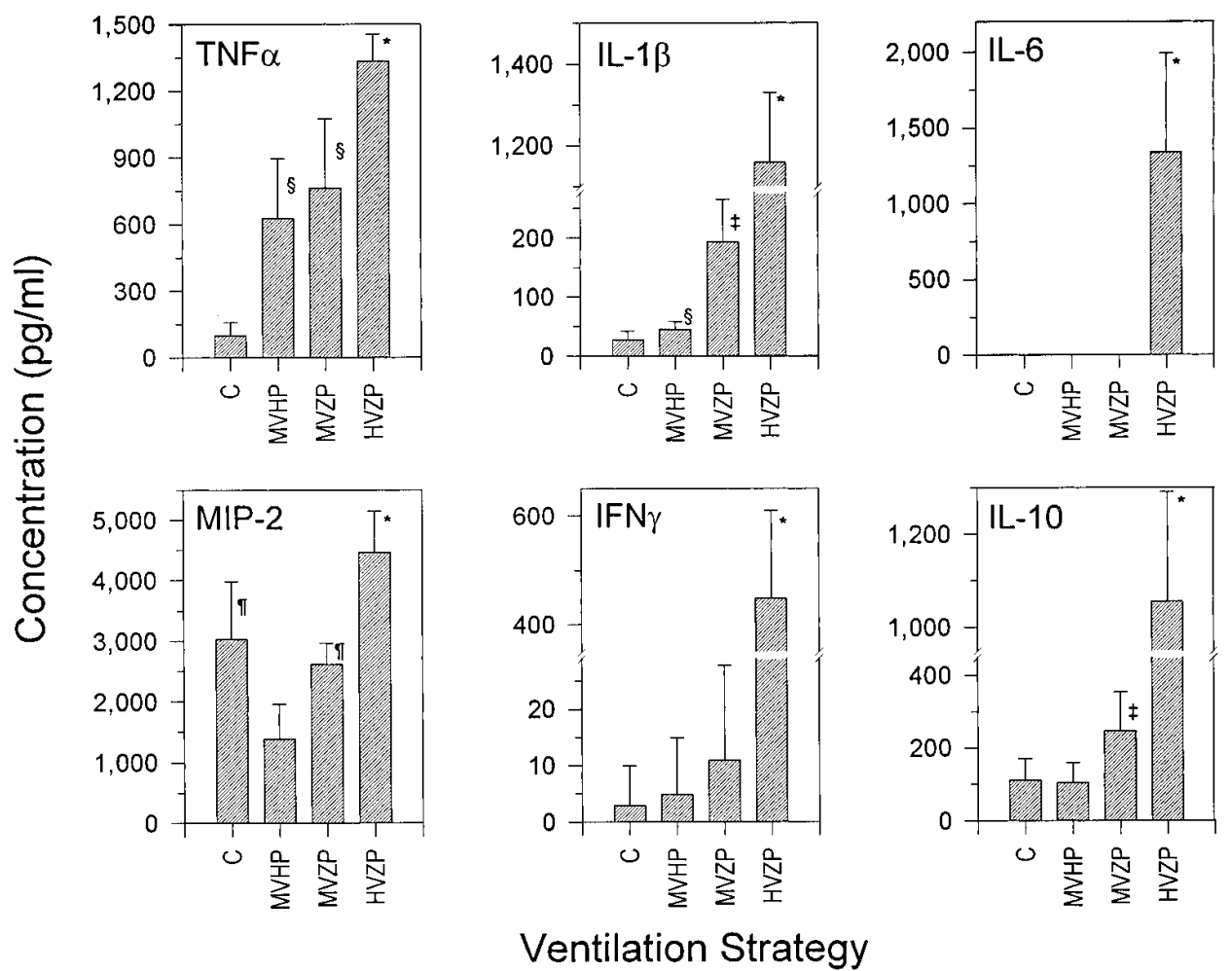

Figure 3. Effect of ventilation strategy on absolute lung lavage cytokine concentrations for the LPSinjected groups. The pattern of lavage cytokines seen in response to ventilation strategy was similar to the saline-treated groups except for MIP-2, in which the control group (C) had comparable levels to the MVZP group (both increased significantly vs. the MVHP group). $* P<0.05$ vs. Control, MVHP, MVZP; ${ }^{\ddagger} P<0.05$ vs. Control, MVHP; ${ }^{\S} P<0.05$ vs. Control; ${ }^{\pi} P<$ 0.05 vs. MVHP. 


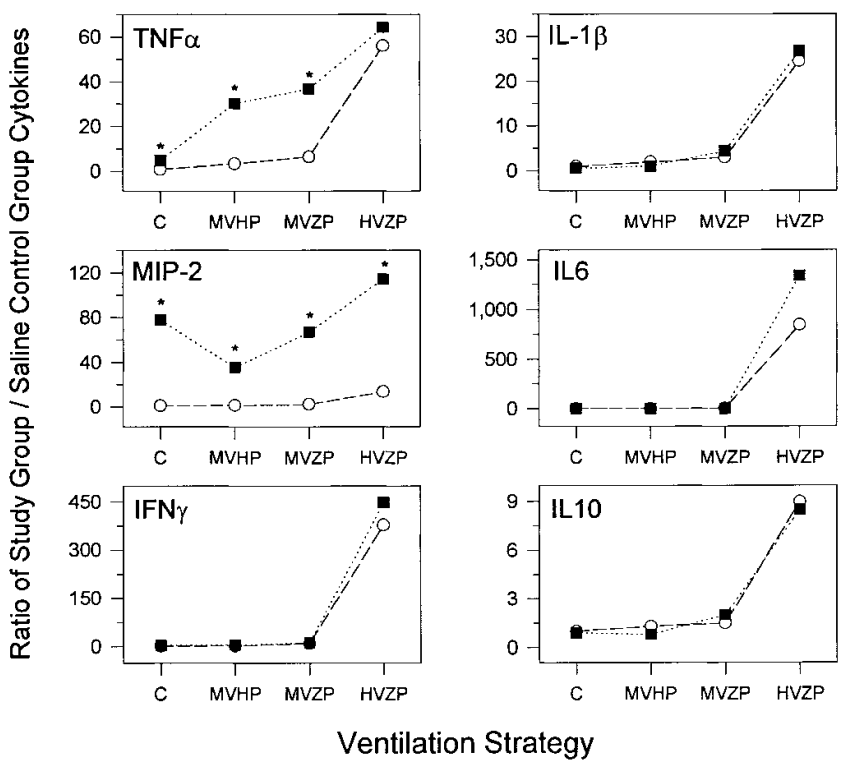

Figure 4. Ratio of study group BAL cytokine concentrations relative to saline-treated controls. LPS ( $\mathbf{\square})$ pretreatment resulted in significantly increased levels of TNF $\alpha$ for three of the ventilatory strategies (i.e., an approximately 5 -fold increase for $\mathrm{C}$, an approximately 30 fold increase for MVHP, and an approximately 37 -fold increase for MVZP) as compared to saline-treated $(O)$ controls. LPS also increased levels of MIP-2 for all four ventilatory strategies, whereas no significant changes were seen with the other four cytokines assessed. As IL- 6 and IFN $\gamma$ were undetectable in saline-treated controls, an arbitrary value of 1 was assigned to allow comparison. $* P<0.05$ vs. saline treated group.

were found in the control lungs $(\mathrm{C})$, and the highest levels in the high volume zero PEEP group (HVZP). Levels of the antiinflammatory cytokine IL-10 paralleled the increases seen in the inflammatory cytokines.

The absolute concentrations for the lavage cytokines in the animals treated with LPS are shown in Fig. 3. The effect of ventilatory strategy in the LPS groups on lung lavage cytokines was comparable to that observed in saline-treated animals with two notable exceptions. First, at the time point assessed (i.e., $3 \mathrm{~h}$ from injection of LPS), LPS caused a significant increase in both TNF $\alpha$ and MIP-2. This is illustrated in Fig. 4, which depicts the increase in cytokine levels for each strategy relative to the cytokine levels in the saline-treated control groups. For $\mathrm{TNF} \alpha$, the increase with LPS was observed in three of the four ventilatory strategies (C, MVHP, MVZP). LPS treatment did not produce a further significant increase in production of TNF $\alpha$ protein for the ventilatory strategy with the maximal effect on cytokine levels (HVZP). Second, MIP-2 in the LPS-treated control lungs (C) was markedly increased, and had levels comparable to those of MVZP, and significantly greater than those with MVHP ventilation $(P<0.05)$.

At the transcriptional level, similar to the increases observed in the levels of lavage cytokines, c-fos mRNA was found to increase with the different ventilatory strategies (Fig. 5). LPS did not have a significant effect on c-fos mRNA levels. $\mathrm{TNF} \alpha \mathrm{mRNA}$ in the saline-treated animals was found to increase with three of the ventilatory strategies as compared to the controls (Fig. 6). The increase, however, was less than that

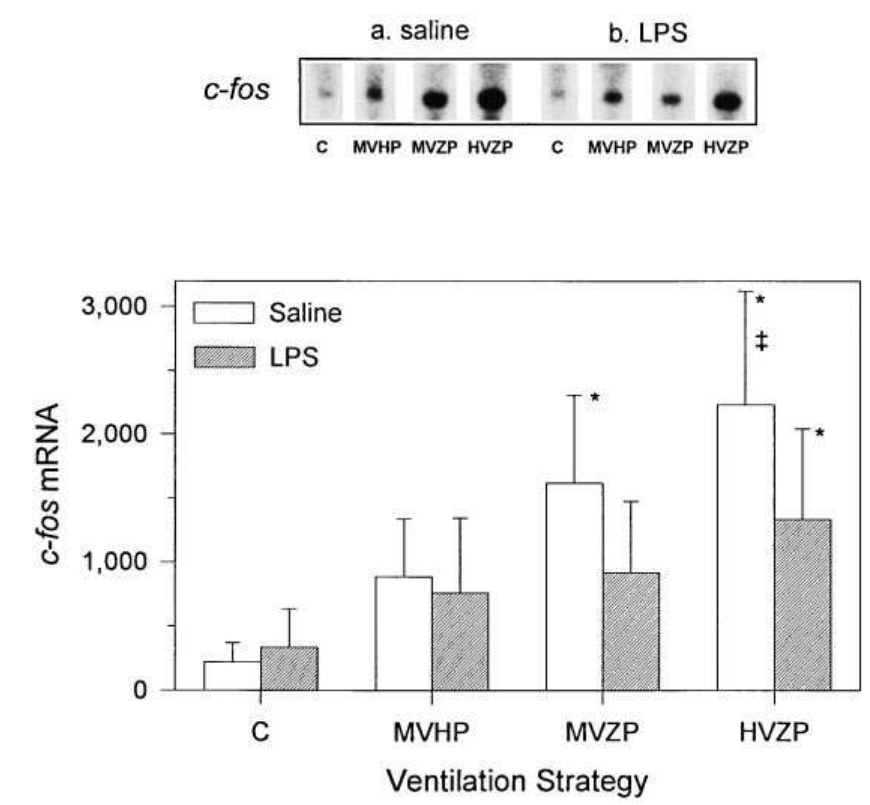

Figure 5. Northern blot analysis of lung homogenate c-fos mRNA for the various ventilation strategies. Densitometric values for c-fos were standardized to $28 \mathrm{~S}$ ribosomal RNA. A similar trend to that observed for the BAL cytokine concentrations was seen in both saline- and LPS-treated animals. The presence or absence of LPS was not found to make a significant difference in c-fos mRNA levels. $* P<0.05$ vs. Control; ${ }^{\ddagger} P<0.05$ vs. MVHP.
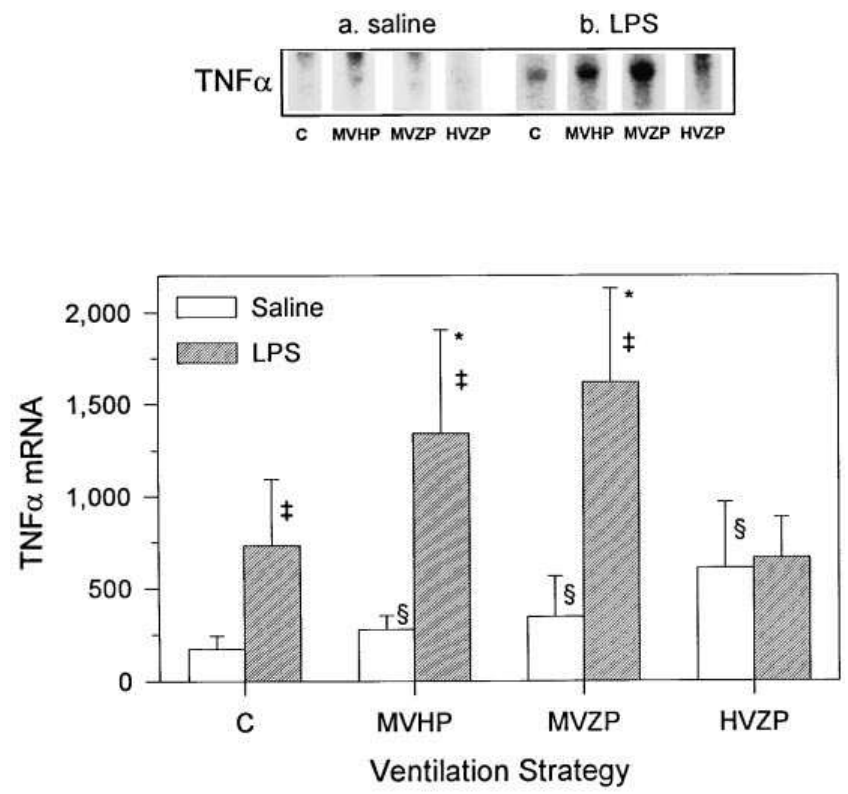

Figure 6. Northern blot analysis of lung homogenate TNF $\alpha$ mRNA levels for the various ventilation strategies. Densitometric values for TNF $\alpha$ were standardized to $28 \mathrm{~S}$ ribosomal RNA. TNF $\alpha$ mRNA in the saline-treated animals increased for three of the ventilatory strategies as compared to the controls $\left({ }^{\S} P<0.05\right.$ vs. Control). In LPStreated animals, TNF $\alpha$ mRNA was significantly greater for MVHP and MVZP as compared to controls or HVZP ( $* P<0.05$ vs. Control HVZP). Within ventilatory strategies, LPS was found to increase TNF $\alpha$ mRNA for three of the four ventilation strategies used (C, MVHP, MVZP; $\left.{ }^{\ddagger} P<0.05\right)$. 
observed in TNF $\alpha$ protein (i.e., saline-treated HVZP vs. control: $\approx 3.5$-fold increase in mRNA versus $\approx 56$-fold increase in protein). In contrast to c-fos, LPS resulted in a further significant increase in TNF $\alpha$ mRNA for three of the four ventilation strategies (C, MVHP, MVZP). However, in the HVZP groups, LPS did not further increase either TNF $\alpha$ protein or mRNA.

Assessment of IL-1 $\beta$ by ELISA in the lung lavage of nonseptic lungs (ventilated with room air supplemented with 5\% $\mathrm{CO}_{2}$ ) revealed a similar trend to that observed with room air alone $(\mathrm{HVZP}>\mathrm{MVZP}>\mathrm{MVHP} \approx \mathrm{C} ; P<0.05)$. There were no significant differences in absolute concentrations of IL-1 $\beta$ as compared to room air alone, except for a lower value in the HVZP group $(524 \pm 304.3 \mathrm{pg} / \mathrm{ml})$. The increase relative to the Control ventilation group, however, was similar (26.9-fold with $5 \% \mathrm{CO}_{2}$ vs. 24.5-fold). By Northern analysis, levels of mRNA for $\mathrm{TNF} \alpha$ were not significantly different for the lavaged (left) versus the unlavaged (right) lung.

\section{Discussion}

In this study, the effect of mechanical ventilation on production of various inflammatory and anti-inflammatory mediators in the lung was assessed both in the presence and absence of LPS-induced sepsis. Different levels of lung lavage cytokines, as well as differential tissue expression of an immediate early response gene (c-fos), were observed with the various ventilation strategies. Our findings support the concept that mechanical ventilation can have a significant influence on the inflammatory/anti-inflammatory milieu of the normal or septic lung, and thus may play a role in either initiating or propagating a local as well as a systemic inflammatory response.

Over the past $20 \mathrm{yr}$ we have developed an increased appreciation that mechanical ventilation per se can initiate or augment lung injury $(2,19)$. Histologically, lung injury similar to that seen with ARDS has been found in lungs from various species ventilated with extremes of volumes or pressures (2). In response, a number of ventilatory strategies have been proposed in an attempt to minimize iatrogenic injury (4). Gains in survival of patients developing acute respiratory distress syndrome, however, remain disappointing (3). It appears that ARDS is often the forerunner of a systemic inflammatory response that culminates in multiple organ dysfunction syndrome (MODS) and death $(3,5)$. One hypothesis to explain this observation is that mechanical ventilation serves to initiate and/or potentiate an inflammatory response in the lung that acts as a nidus for the development of a systemic inflammatory response.

Although no studies to date have addressed whether mechanical ventilation per se can lead to changes in production of inflammatory mediators, several studies lend support to the plausibility of this postulate. In a surfactant-deficient model of the respiratory distress syndrome, Kawano et al. found that a number of structural changes (i.e., increased lung permeability, development of hyaline membranes) originally attributed to physical disruption by conventional mechanical ventilation were in fact mediated by activated granulocytes (9). Using a similar model, Imai et al. found less platelet-activating factor and thromboxane- $\mathrm{B}_{2}$ in lung lavage fluid and less lung injury with high frequency oscillatory ventilation as opposed to pressure control ventilation (10). Concurrently, research in mechanotransduction has revealed that physical forces play a pivotal role in cell function. In the lung, cell stretch has been found to be important in lung growth and development $(12,14)$ as well as surfactant production (13). Among the proposed mechanisms by which cellular deformation is converted into changes in cell phenotype or metabolism are $(a)$ direct conformational changes in membrane-associated molecules leading to activation of downstream messenger systems, $(b)$ activation or inactivation of stretch-sensitive ion channels, and/or (c) release of paracrine or autocrine factors $(20,21)$. As both the degree and pattern of mechanical stimuli have been shown to be important, it is reasonable to postulate that mechanical ventilation may lead to alterations in gene expression or cellular metabolism that contribute to the development of lung injury $(14,15)$.

Given that we wished to look at the response of the lung to different ventilatory strategies independent of changes in cardiac output caused by the different ventilatory patterns and independent of influx of cytokines from the systemic circulation, an ex vivo non-perfused lung model was used. This model does have its limitations. Tissue responses to stress may not be identical to those seen in vivo, and a priming effect of ischemia on lung expression of various mediators cannot be ruled out. However, all study groups were exposed to the same $2 \mathrm{~h}$ period of nonperfusion, which is within the known limits of lung viability (22-24).

Since end inspiratory lung volume and level of PEEP had been shown in previous studies to correlate with development of ventilator-induced injury, two lung overdistention strategies with identical end-inspiratory volumes but different levels of PEEP were assessed (MVHP, HVZP). Although large, these volumes likely produced overdistention similar in magnitude to the regional overdistention observed in patients with lung injury. Gattinoni et al. have demonstrated that patients with early ARDS have collapsed dependent lung regions (25). As such, the delivered tidal volume predominantly ventilates the reduced aerated portion of the lung, causing overdistention of these alveolar units (26). To assess the relative importance of lung stretch and PEEP, we also studied an intermediate lung distention strategy (MVZP), and a low distention non-injurious control strategy (C).

Lung lavage levels of cytokines were examined, as they have been shown to be key modulators of injury and inflammation. Supplementation (or blocking) of various inflammatory cytokines has been found to induce (or abrogate) lung injury (27-30). In light of the complexity and redundancy of the cytokine network, however, caution must be used in interpreting changes of individual cytokines (31-33). As such, we looked at levels of a number of key inflammatory (TNF $\alpha$, IL$1 \beta$, IL-6, IFN $\gamma$ ), chemotactic (MIP-2), and anti-inflammatory (IL-10) cytokines (31-36). We chose a single time point at which detection of increased expression of both cytokine protein and mRNA would be expected for the majority of these mediators. Although this reduces our ability to draw conclusions about the order of induction of the various cytokines, it does provide a cross-sectional analysis of the early inflammatory response to a number of different ventilatory strategies.

A novel finding was the differential expression of lung lavage cytokines in response to various ventilatory strategies. For lungs randomized to intravenous saline, a similar effect on lung lavage cytokines was seen for all six cytokines assessed (Fig. 2). The highest levels of inflammatory mediators were seen in those ventilatory strategies with no positive end expiratory pressure $(\mathrm{MVZP}<\mathrm{HVZP})$. These groups were also found to develop significant reductions in lung compliance 
(Fig. 1). Taken together, these findings offer a possible explanation for the observation in previous studies that mechanical ventilation strategies that allow repetitive lung collapse lead to increased neutrophil infiltration and surfactant inactivation (9, 10, 37). Inflammatory cytokines have been shown to inhibit surfactant synthesis and adsorption (38-40). Elevated BAL levels of chemokines such as MIP-2 are known as well to result in increased infiltration of activated inflammatory cells, which in turn can further disrupt surfactant function. Although our model was nonperfused, it is known that even in lungs perfused with physiologic salt solutions for several hours, a significant number of leukocytes are retained (41).

Surfactant inactivation may have also developed in these two zero PEEP groups secondary to repetitive compression and reexpansion of the surfactant film, as well as squeezing of surfactant out of the alveoli with recurrent alveolar collapse (37). As surfactant has been shown to modulate secretion of cytokines and activity of a number of cells involved in the inflammatory cascade $(42,43)$, a reduction of functional surfactant may have been responsible in part for the increased levels of lung lavage cytokines seen with the MVZP and HVZP ventilation strategies.

Acting in conjunction with the above, structural injury as a result of the shear forces generated by the repetitive opening and closing of distal small airways in the absence of PEEP may have contributed to the production of inflammatory mediators $(37,44,45)$. This latter mechanism may account for the magnitude of the synergistic effect of large tidal volume and zero PEEP (e.g., 56-fold increase in HVZP lavage TNF $\alpha$ vs. control) as compared to either similar end-inspiratory stretch (MVHP, 3-fold increase in TNF $\alpha$ vs. control) or a lesser degree of stretch in the absence of PEEP (MVZP, 6-fold increase in $\mathrm{TNF} \alpha$ vs. control).

The minimal increase in cytokines we found with MVHP ventilation does not contradict prior studies implicating endinspiratory lung volume as a major factor in the development of lung injury. In vivo ventilation with high volumes leads to a number of systemic and hemodynamic effects that can contribute to the pathogenesis of lung injury (19). In addition, at high lung volumes in vivo extravasation of intravascular cells and fluid may occur as a result of stress failure of pulmonary capillaries (1). Indeed, even in our ex vivo model we found an increase in lung lavage total protein with all three injurious ventilatory strategies as compared to control ventilation. Miles et al. reported a similar finding in excised lungs ventilated at different temperatures (46). Given that Mathieu-Costello found comparable increases in the number of ultrastructural breaks in the alveolar-capillary membrane for equivalent increases in either transpulmonary pressure or capillary transmural pressure (47), influx of retained plasma proteins may have been responsible in part for the observed increases in lavage proteins. Inflammatory proteins (e.g., cytokines, complement, proteases) and release of matrix or intracellular proteins secondary to lung injury likely also contributed. Whether the lavage proteins played a role in the increased production/release of cytokines, or occurred in response to the inflammatory cytokines and lung injury, requires further investigation.

To investigate whether the changes in cytokines were due to differences in intracellular $\mathrm{pH}$ as a result of the various ventilation strategies, we repeated analysis of lung lavage levels of IL-1 $\beta$ from lungs ventilated with room air supplemented with $5 \% \mathrm{CO}_{2}$. Similar increases in IL-1 $\beta$ as compared to ventilation with room air, were found. Thus, loss of intracellular $\mathrm{CO}_{2}$ was not the principle mechanism responsible for the changes in mediators we observed.

As underlying lung inflammation is thought to sensitize the lung to further injury by mechanical ventilation (48), the effect of intravenous LPS an hour before randomization in each of the four ventilatory strategies was also assessed. Based on circulating blood $\mathrm{TNF} \alpha$ concentrations prior to lung harvest, a systemic inflammatory response was indeed present in all the LPS-treated rats. The resultant lung lavage cytokine profiles, however, were not significantly changed as compared to the saline-treated animals, with the exception of TNF $\alpha$ and MIP-2. This may be due to the timepoint at which we sampled the lung lavage, as transcripts for TNF $\alpha$ and MIP-2 have been shown to peak early (i.e., $\approx 1 \mathrm{~h}$ ) after LPS exposure, whereas IL-1 $\beta$ and IL-6 have been shown to peak at approximately $6 \mathrm{~h}$ (49). It is noteworthy, however, that mechanical ventilation for 2 hours was found to induce changes in even these later response cytokines. This suggests that the mechanisms by which each stimulus (i.e., ventilation vs. LPS) leads to cytokine expression are quite distinct.

At the transcriptional level, TNF $\alpha$ mRNA increased with 3 of the ventilatory strategies (MVHP, MVZP, HVZP) in the saline-treated animals. The effect of ventilation strategy on mRNA, however, was much less than that observed at the protein level (e.g., saline-treated HVZP vs. control: $\approx 3.5$-fold increase in mRNA versus $\approx 56$-fold increase in protein). This is consistent with prior studies demonstrating that TNF $\alpha$ expression is primarily regulated posttranscriptionally $(31,50)$. LPS resulted in a further increase in TNF $\alpha$ mRNA for the $C$, MVHP, and MVZP groups, but no further increase was found with HVZP ventilation for either TNF $\alpha$ protein or mRNA. In light of the high levels of $\mathrm{TNF} \alpha$ protein found in the lung lavage fluid, it may be that any further increase in TNF $\alpha$ was limited by substrate availability. Alternatively, lung lavage TNF $\alpha$ may have peaked earlier as a result of the combined effect of LPS and HVZP ventilation, or increased release and activation of proteases and RNases in this group may have resulted in increased RNA and protein degradation.

For c-fos, a similar effect of ventilation strategy on mRNA level was seen as that observed for the cytokine levels in the lung lavage (Fig. 4). We chose to examine c-fos, as it is induced as one of the earliest nuclear responses of many cell types following a variety of stimuli (51). In addition, c-fos has a stretchresponsive promoter element, and has been used as a nuclear marker of transcription in a number of mechanotransduction studies (51-53). Fos transcription factors also play an important role in mediating gene transcription and a number of cytokine responses (54-56). As all three of the higher volume ventilatory strategies had increased levels of c-fos as compared to the controls, cell stretch may have played a role in induction of c-fos transcription in our model. However, significantly higher levels of c-fos were seen in the HVZP as opposed to the MVHP group at the same degree of end-inspiratory lung stretch. Thus, other nonspecific stimuli such as cell injury (54) (or pattern of cell stretch $[14,15]$ ) were also involved in c-fos induction.

Further studies are necessary to determine the cell types responsible for the observed changes in protein and mRNA in response to ventilatory strategy. Intraalveolar macrophages are prime candidates, as they have been shown to be capable of producing a number of cytokines $(57,58)$. However, given 
that we found no difference in TNF $\alpha$ mRNA in homogenates of lungs lavaged versus non-lavaged, alveolar macrophages (or at least those removed by lung lavage), are not the sole cells involved. There is some evidence from the literature that type II pneumocytes may play a pivotal role in cytokine networking within the lung $(59,60)$. In vivo intravascular cells likely make a significant contribution to the inflammatory milieu as well. Since microscopically, the distribution of ventilator-associated lung injury (airway vs. alveolar) has been found to vary depending on the ventilation parameters used (e.g., level of PEEP) $(37,61)$, the various cells involved in mediator release will probably also depend on the particular ventilation strategy used.

Irrespective of the specific mechanism (i.e., cell stretch, reduced surfactant, structural injury, or multifactorial), the observation that mechanical ventilation per se can alter lung cytokines and gene expression has several implications. First, this may explain the observation that many patients with ARDS go on to develop and die from multiple organ dysfunction syndrome, rather than from their underlying lung disease. Perhaps mechanical ventilation initiates a local inflammatory reaction with release of cytokines. As compartmentalization of alveolar cytokines can be lost in injured lungs, systemic release may occur leading to initiation or propagation of a systemic inflammatory response $(62,63)$. Second, to a large extent, current approaches for preventing ventilator-induced lung injury have focused on minimizing fraction of inspired oxygen, and manipulating ventilator parameters to limit lung stretch. Despite this, ventilator-induced lung injury remains a significant problem in the care of critically ill patients (4). The present study suggests a novel mechanism of injury: although the inciting factor may be mechanical, it is but the first step in the initiation of a number of cellular responses leading to lung injury. If correct, this could lead to a paradigm shift in which therapies to prevent ventilator-induced lung injury are based not only on manipulating pressures or volumes in the lung, but also on interventions that are not mechanically based. Further studies are needed to clarify the specific cellular mechanisms involved to design novel therapies to down-regulate or up-regulate various members of the inflammatory/anti-inflammatory cascade.

\section{Acknowledgments}

The authors wish to acknowledge the technical assistance of Ioan Mates, Yanchun Wang, and Dr. Annette Boehler; the guidance with regards to the statistical analysis by Dr. S. Bull; and the pathology expertise of Dr. B. Mullen. We also greatly appreciate the critical appraisal of Dr. Mingyao Liu in the preparation of this manuscript.

This work was supported by a grant from the Medical Research Council of Canada. Dr. Tremblay is a fellow of the Canadian Cystic Fibrosis Foundation.

\section{References}

1. West, J.B., and O. Mathieu-Costello. 1992. Stress failure of pulmonary capillaries: role in lung and heart disease. Lancet. 340:762-767.

2. Parker, J.C., L.A. Hernandez, and K.J. Peevy. 1993. Mechanisms of ventilator-induced lung injury. Crit. Care Med. 21:131-143.

3. Hudson, L.D. 1989. Survival data in patients with acute and chronic lung disease requiring mechanical ventilation. Am. Rev. Respir. Dis. 140:19S-24S.

4. Slutsky, A.S. 1994. Consensus conference on mechanical ventilation January 28-30, 1993 at Northbrook, Illinois, USA. Intensive Care Med. 20:6479.

5. Montgomery, A.B., M.A. Stager, C.J. Caricco, and L.D. Hudson. 1985. Causes of mortality in patients with the adult respiratory distress syndrome.
Am. Rev. Respir. Dis. 132:485-489.

6. Meduri, G., G. Kohler, S. Headley, E. Tolley, F. Stentz, and A. Postlethwaite. 1995. Inflammatory Cytokines in the BAL of Patients with ARDS. Chest. 108:1303-1314.

7. Reid, P.T., S.C. Donnelly, and C. Haslett. 1995. Inflammatory predictors for the development of the adult respiratory distress syndrome. Thorax. 50: 1023-1026.

8. Donnelly, S.C., and C. Haslett. 1992. Cellular mechanisms of acute lung injury:implications for future treatment of the adult respiratory distress syndrome. Thorax. 47:260-263.

9. Kawano, T., S. Mori, M. Cybulsky, R. Burger, A. Ballin, E. Cutz, and A.C. Bryan. 1987. Effect of granulocyte depletion in a ventilated surfactantdepleted lung. J. Appl. Physiol. 62:27-33.

10. Imai, Y., T. Kawano, K. Miyasaka, M. Takata, T. Imai, and K. Okuyama. 1994. Inflammatory chemical mediators during conventional ventilation and during high frequency oscillatory ventilation. Crit. Care Med. 150: 1550-1554.

11. Sugiura, M., P.R. McCulloch, S. Wren, R.H. Dawson, and A.B. Froese. 1994. Ventilator pattern influences neutrophil influx and activation in atelectasis-prone rabbit lung. J. Appl. Physiol. 77:1355-1365.

12. Liu, M., J. Xu, J. Liu, M.E. Kraw, A.K. Tanswell, and M. Post. 1995. Mechanical strain-enhanced fetal lung cell proliferation is mediated by phospholipases C and D and protein kinase C. Am. J. Physiol. 268:L729-L738.

13. Wirtz, H.R.W., and L.G. Dobbs. 1990. Calcium mobilization and exocytosis after one mechanical stretch of lung epithelial cells. Science (Wash. DC). 250:1266-1269.

14. Rannels, D.E. 1989. Role of physical forces in compensatory growth of the lung. Am. J. Physiol. 257:L179-L189.

15. Vandenburgh, H.H. 1992. Mechanical forces and their second messengers in stimulating cell growth in vitro. Am. J. Physiol. 262:R350-R355.

16. Sadoshima, J., and S. Izumo. 1993. Mechanical stretch rapidly activates multiple signal transduction pathways in cardiac myocytes: potential involvement of an autocrine/paracrine mechanism. EMBO J. 12:1681-1692.

17. Chomczynski, P., and N. Sacchi. 1987. Single-step method of RNA isolation by acid guanidinium thiocyanate-phenol-chloroform extraction. Anal. Biochem. 162:156-159.

18. Norman, G.R., and D.L. Streiner. 1994. Biostatistics. Mosby-Year Book Inc., St. Louis, MO.

19. Bezzant, T.B., and J.D. Mortensen. 1994. Risks and hazards of mechanical ventilation: a collective review of published literature. Disease-A-Month. XL:581-640.

20. Watson, P.A. 1991. Function follows form: generation of intracellular signals by cell deformation. FASEB J. 5:2013-2019.

21. Sachs, F. 1991. Mechanical transduction by membrane ion channels: a mini review. Mol. Cell. Biochem. 104:57-60.

22. Alessandrini, F., A.M. D'Armini, C.S. Roberts, R.L. Reddick, and T.M. Egan. 1994. When does the lung die? II. Ultrastructural evidence of pulmonary viability after "death". J. Heart Lung Transplant. 13:748-757.

23. Ardekarni, R.G., P.L. Faber, and E.J. Beattie, Jr. 1970. Pulmonary function after various periods of ischemia in the canine lung. J. Thorac. Cardiovasc. Surg. 59:607-612.

24. Homatas, J., L. Bryant, and B. Eiseman. 1968. Time limits of cadaver lung viability. J. Thorac. Cardiovasc. Surg. 56:132-140.

25. Gattinoni, L., A. Pesenti, A. Torresin, S. Baglioni, M. Rivolta, F. Rossi, F. Scarani, R. Marcolin, and G. Cappelletti. 1986. Adult respiratory distress syndrome profiles by computed tomography. J. Thorac. Imag. 1:25-30.

26. Gattinoni, L., A. Pesenti, S. Baglioni, M. Rivolta, and P. Pelosi. 1988. Inflammatory pulmonary edema and positive end-expiratory pressure: correlation between imaging and physiologic studies. J. Thorac. Imag. 3:59-64.

27. Chernoff, A.E., E.V. Granowitz, L. Shapiro, E. Vannier, G. Lonnemann, J.B. Angel, J.S. Kennedy, A.R. Rabson, S.M. Wolff, and C.A. Dinarello. 1995. A randomized controlled trial of IL-10 in humans. Inhibition of inflammatory cytokine production and immune responses. J. Immunology. 154:54925499 .

28. Abraham, E., W.F. Coulson, M.D. Scwartz, and J. Allbee. 1994. Effects of therapy with soluble tumor necrosis factor receptor fusion protein on pulmonary cytokine expression and lung injury following haemorrhage and resuscitation. Clin. Exp. Immunol. 98:29-34.

29. Jonathan, A.L., M.E. Bodman, O.J. Cho, S. Rohrbach, O.K. Reiss, J.L. Vannice, and J.E. Repine. 1994. Post-insult treatment with interleukin-1 receptor antagonist decreases oxidative lung injury in rats given intratracheal interleukin-1. Am. J. Respir. Crit. Care Med. 150:109-112.

30. Sekido, N., N. Mukaida, A. Harada, I. Nakanishi, Y. Watanabe, and K. Matsushima. 1993. Prevention of lung reperfusion injury in rabbits by a monoclonal antibody against interleukin-8. Nature (Lond.). 365:654-657. 788.

31. Kelley, J. 1990. Cytokines of the Lung. Am. Rev. Respir. Dis. 141:765-

32. Bendtzen, K. 1994. Cytokines and natural regulators of cytokines. Immunol. Lett. 43:111-123.

33. Elias, J.A., B. Freundlich, J.A. Kern, and J. Rosenbloom. 1990. Cytokine networks in the regulation of inflammation and fibrosis in the lung. Chest. 97:1439-1445 
34. Li, X.Y., K. Donaldson, D. Brown, and W. MacNee. 1995. The Role of Tumor Necrosis Factor in Increased Airspace Epithelial Permeability in Acute Lung Inflammation. Am. J. Respir. Cell Mol. Biol. 13:185-195.

35. Driscoll, K.E. 1994. Macrophage inflammatory proteins: biology and role in pulmonary inflammation. Exp. Lung Res. 20:473-490.

36. Moore, K.W., A. O'Garra, R. de Waal Malefyt, P. Vieira, and T.R. Mosmann. 1993. Interleukin-10. Annu. Rev. Immunol. 11:165-190.

37. Muscedere, J.G., J.B.M. Mullen, K. Gan, and A.S. Slutsky. 1994. Tidal ventilation at low airway pressures can augment lung injury. Am. J. Respir. Crit. Care Med. 149:1327-1334.

38. Bachurski, C.J., G.S. Pryhuber, S.W. Glasser, S.E. Kelley, and J.A. Whitsett. 1995. Tumor necrosis factor inhibits surfactant protein C gene transcription. J. Biol. Chem. 270:19402-19407.

39. Arias-Diaz, J., E. Vara, C. Garcia, M. Gomez, and J.L. Balibrea. 1996. Tumor necrosis factor-alpha inhibits synthesis of surfactant by isolated human type II pneumocytes. Eur. J. Surg. 159:541-549.

40. Vara, E., J. Arias-Diaz, C. Garcia, J. Hernandez, and J.L. Balibrea. 1995. Both prostaglandin E2 and nitric oxide sequentially mediate the tumor necrosis factor-alpha induced inhibition of surfactant synthesis by human type II pneumocytes. Arch. Surg. 130:1279-1286.

41. Seibert, A.F. J. Haynes, and A. Taylor. 1993. Ischemia-reperfusion injury in the isolated rat lung. Role of flow and endogenous leukocytes. Am. Rev. Respir. Dis. 147:270-275.

42. Pison, U., M. Max, A. Neuendank, S. Weibbach, and S. Pietschmann. 1994. Host defense capacities of pulmonary surfactant: evidence for 'non-surfactant' functions of the surfactant system. Eur. J. Clin. Invest. 24:586-599.

43. Geertsma, M.F., W.L. Teeuw, P.H. Nibbering, and R. Van Furth. 1994. Pulmonary surfactant inhibits activation of human monocytes by recombinant interferon-gamma. Immunology. 82:450-456.

44. Laskin, D.L., R.A. Soltys, R.A. Berg, and D. Riley. 1994. Activation of alveolar macrophages by native and synthetic collagen-like polypeptides. Am. J. Respir. Cell Mol. Biol. 10:58-64.

45. Nathan, C.F. 1987. Neutrophil activation on biological surfaces. J. Clin. Invest. 80:1550-1560.

46. Miles, P.R., L. Bowman, and D.G. Frazer. 1995. Properties of lavage material from excised lungs ventilated at different temperatures. Respir. Physiol. 101:95-108.

47. Mathieu-Costello, O., and J.B. West. 1994. Are pulmonary capillaries susceptible to mechanical stress? Chest. 105:102-108.

48. Dreyfuss, D., P. Soler, and G. Saumon. 1995. Mechanical ventilationinduced pulmonary edema. Interaction with previous lung alterations. Am. J. Respir. Crit. Care Med. 151:1568-1575.

49. Xing, Z., M. Jordana, H. Kirpalani, K.E. Driscoll, T.J. Schall, and J. Gauldie. 1994. Cytokine expression by neutrophils and macrophages in vivo: endotoxin induces tumor necrosis factor-alpha, macrophage inflammatory protein-s, interleukin-1beta, and interleukin-6 but not RANTES or transforming growth factor-beta1 mRNA expression in acute lung inflammation. Am. J. Respir. Cell Mol. Biol. 10:148-153.

50. Beutler, B., N. Kronchin, I.W. Milsark, C. Luedke, and A. Cerami. 1986 Control of cahectin (tumor necrosis factor) synthesis: mechanisms of endotoxin resistance. Science (Wash. DC). 232:977-980.

51. Sadoshima, J., T. Takahashi, L. Jahn, and S. Izumo. 1992. Roles of mechano-sensitive ion channels, cytoskeleton, and contractile activity in stretch-induced immediate-early gene expression and hypertrophy of cardiac myocytes. Proc. Natl. Acad. Sci. USA. 89:9905-9909.

52. Komuro, I., T. Kaida, Y. Shibazaki, M. Kurabayashi, Y. Katoh, E. Hoh, F. Takaku, and Y. Yazaki. 1990. Stretching cardiac myocytes stimulates protooncogene expression. J. Biol. Chem. 265:3595-3598.

53. Sadoshima, J., L. Jahn, T. Takahashi, T.J. Kulik, and S. Izumo. 1992. Molecular characterization of the stretch-induced adaptation of cultured cardiac cells. J. Biol. Chem. 267:10551-10560.

54. Reddy, E.P., A.M. Skalka, and T. Curran. 1988. The Oncogene Handbook. Elsevier, Amsterdam.

55. Klampfer, L., T.H. Lee, W. Hsu, J. Vilcek, and S. Chen-Kiang. 1994 NF-IL6 and AP-1 cooperatively modulate the activation of the TSG-6 gene by tumor necrosis factor alpha and interleukin-1. Mol. Cell. Biol. 14:6561-6569.

56. Angel, P., and M. Karin. 1991. The role of jun,fos, and the AP-1 complex in cell-proliferation and transformation. Biochim. Biophys. Acta. 1072: $129-157$.

57. Nathan, C.F. 1987. Secretory products of macrophages. J. Clin. Invest. 79:319-326.

58. Tran Van Nhieu, J., B. Misset, F. Lebargy, J. Carlet, and J.F. Bernaudin. 1993. Expression of tumor necrosis factor-a gene in alveolar macrophages from patients with the adult respiratory distress syndrome. Am. Rev. Respir. Dis. 147: 1585-1589.

59. Crestani, B., P. Cornillet, M. Dehoux, C. Rolland, M. Guenounou, and M. Aubier. 1994. Alveolar type II cells produce interleukin-6 in vitro and in vivo. J. Clin. Invest. 94:731-740.

60. Nash, J.R.G., P.J. McLaughlin, C. Hoyle, and D. Roberts. 1991. Immunolocalization of tumor necrosis factor alpha in lung tissue from patients dying with adult respiratory distress syndrome. Histopathology Oxf. 19:395-402.

61. Dreyfuss, D., P. Soler, G. Basset, and G. Saumon. 1988. High inflation pressure pulmonary edema. Respective effects of high airway pressure, high tidal volume, and positive end-expiratory pressure. Am. Rev. Respir. Dis. 137: 1159-1164.

62. Tutor, J.D., C.M. Mason, E. Dobard, R.C. Beckerman, W.R. Summer, and S. Nelson. 1994. Loss of compartmentalization of alveolar tumor necrosis factor after lung injury. Am. J. Respir. Crit. Care Med. 149:1107-1111.

63. Debs, R.J., H.J. Fuchs, R. Philip, A.B. Montgomery, E.N. Brunette, D. Liggitt, J.S. Patton, and J.E. Shellito. 1988. Lung-specific delivery of cytokines induces sustained pulmonary and systemic immunomodulation in rats. J. Immunol. 140:3482-3488. 